\title{
Cross-sectional associations between air pollution and chronic bronchitis: an ESCAPE meta-analysis across five cohorts
}

\author{
Yutong Cai, ${ }^{1}$ Tamara Schikowski, ${ }^{2,3,4}$ Martin Adam, ${ }^{2,3}$ Anna Buschka, ${ }^{4}$ \\ Anne-Elie Carsin, ${ }^{5}$ Benedicte Jacquemin,,${ }^{5,6}$ Alessandro Marcon, ${ }^{8}$ \\ Margaux Sanchez, ${ }^{6,7}$ Andrea Vierkötter, ${ }^{4}$ Zaina Al-Kanaani, ${ }^{1}$ Rob Beelen, ${ }^{9}$ \\ Matthias Birk, ${ }^{10}$ Bert Brunekreef, ${ }^{9}$ Marta Cirach, ${ }^{5}$ Françoise Clavel-Chapelon, ${ }^{7,11}$ \\ Christophe Declercq, ${ }^{12, \dagger}$ Kees de Hoogh, ${ }^{1,2,3}$ Audrey de Nazelle, ${ }^{5,13}$

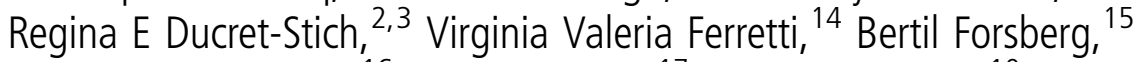 \\ Margaret W Gerbase, ${ }^{16}$ Rebecca Hardy, ${ }^{17}$ Joachim Heinrich, ${ }^{10}$ Gerard Hoek ${ }^{9}$ \\ Debbie Jarvis, ${ }^{1,18}$ Dirk Keidel, ${ }^{2,3}$ Diana Kuh, ${ }^{17}$ Mark J Nieuwenhuijsen, ${ }^{5}$ \\ Martina S Ragettli, ${ }^{2,3}$ Andrea Ranzi, ${ }^{19}$ Thierry Rochat, ${ }^{16}$ Christian Schindler, ${ }^{2,3}$ \\ Dorothea Sugiri, ${ }^{4}$ Sofia Temam, ${ }^{6,7}$ Ming-Yi Tsai, ${ }^{2,3}$ Raphaëlle Varraso, ${ }^{6,7}$ \\ Francine Kauffmann, ${ }^{6,7}$ Ursula Krämer, ${ }^{4}$ Jordi Sunyer, ${ }^{5}$ Nino Künzli, ${ }^{2,3}$ \\ Nicole Probst-Hensch, 2,3 Anna L Hansell ${ }^{1,20}$
}

- Additional material is published online only. To view please visit the journal online (http://dx.doi.org/10.1136/ thoraxjnl-2013-204352).

For numbered affiliations see end of article.

\section{Correspondence to} Dr Anna Hansell, MRC-PHE Centre for Environment and Health, School of Public Health, Imperial College London, St Mary's Campus, Norfolk Place, London W2 1PG, UK :

a.hansell@imperial.ac.uk

YC, TS and MA contributed equally to this work.

TS, FK UK, JS, NK, NP-H and ALH: Steering Committee ESCAPE Work Package 4 Respiratory Health in Adults.

tDeceased.

Received 14 August 2013 Revised 11 July 2014 Accepted 17 July 2014 Published Online First 11 August 2014

CrossMark

To cite: Cai $Y$,

Schikowski T, Adam M,

et al. Thorax

2014;69:1005-1014.

\section{ABSTRACT}

Background This study aimed to assess associations of outdoor air pollution on prevalence of chronic bronchitis symptoms in adults in five cohort studies (Asthma-E3N, ECRHS, NSHD, SALIA, SAPALDIA) participating in the European Study of Cohorts for Air Pollution Effects (ESCAPE) project.

Methods Annual average particulate matter $\left(\mathrm{PM}_{10}\right.$, $\left.\mathrm{PM}_{2.5}, \mathrm{PM}_{\text {absorbance, }} \mathrm{PM}_{\text {coarse}}\right), \mathrm{NO}_{2}$, nitrogen oxides $\left(\mathrm{NO}_{\mathrm{x}}\right)$ and road traffic measures modelled from ESCAPE measurement campaigns 2008-2011 were assigned to home address at most recent assessments (1998-2011). Symptoms examined were chronic bronchitis (cough and phlegm for $\geq 3$ months of the year for $\geq 2$ years), chronic cough (with/without phlegm) and chronic phlegm (with/ without cough). Cohort-specific cross-sectional multivariable logistic regression analyses were conducted using common confounder sets (age, sex, smoking, interview season, education), followed by meta-analysis. Results 15279 and 10537 participants respectively were included in the main $\mathrm{NO}_{2}$ and $\mathrm{PM}$ analyses at assessments in 1998-2011. Overall, there were no statistically significant associations with any air pollutant or traffic exposure. Sensitivity analyses including in asthmatics only, females only or using back-extrapolated $\mathrm{NO}_{2}$ and $\mathrm{PM}_{10}$ for assessments in 1985-2002 (ECRHS, NSHD, SALIA, SAPALDIA) did not alter conclusions. In never-smokers, all associations were positive, but reached statistical significance only for chronic phlegm with $\mathrm{PM}_{\text {coarse }}$ OR 1.31 (1.05 to 1.64) per $5 \mu \mathrm{g} / \mathrm{m}^{3}$ increase and $\mathrm{PM}_{10}$ with similar effect size. Sensitivity analyses of older cohorts showed increased risk of chronic cough with $\mathrm{PM}_{2.5 a b s}$ (black carbon) exposures. Conclusions Results do not show consistent associations between chronic bronchitis symptoms and current traffic-related air pollution in adult European populations.

\section{Key messages}

What is the key question?

- Is long-term exposure to traffic or ambient air pollution associated with prevalence of cough and phlegm in adult European populations?

\section{What is the bottom line?}

- Current long-term average air pollution levels were not associated with symptoms of chronic bronchitis, cough or phlegm in European adults of all ages living in nine European countries, but there were small increases in reported phlegm in never-smokers associated with coarse particulate matter.

\section{Why read on?}

- This is one of the largest such studies in adults involving $>10000$ individuals in five European cohorts using harmonised exposure and outcome measurements; while most results were null, there was some heterogeneity across findings for cohort assessments at different time points, particularly for black carbon and $\mathrm{NO}_{2}$.

\section{INTRODUCTION}

Chronic cough and phlegm production are common respiratory symptoms. In the past, these were often considered together as the clinical phenotype of chronic bronchitis, ${ }^{1}$ but more recently phlegm ${ }^{2}$ and cough $^{3}$ have been considered separately and may have differing mechanisms-for example, cough may result from central reflex sensitivity ${ }^{4}$ as well as irritation and inflammation. A previous study of young adults found wide geographic variability in 
chronic bronchitis prevalence (0.7-9.7\%) across Europe, but only $30 \%$ of the variability could be explained by differences in smoking habits. ${ }^{5}$ This suggests other potentially modifiable factors-such as air pollution-may be important.

There is good evidence that air pollution triggers exacerbations in patients with COPD, and suggestive evidence of chronic effects of air pollution on the prevalence and incidence of COPD in adults. ${ }^{6}$ Concurrent asthma may give rise to cough and phlegm. Traffic-related air pollution has also been related to onset of childhood asthma, but findings in adults are less clear. ${ }^{7}$ Pathophysiological studies have found associations between long-term exposure to ambient particulate matter (PM) and chronic mucosal inflammation in the lung, ${ }^{8}$ resulting in excessive mucus secretion, coughing and phlegm production. ${ }^{9}$ Previous epidemiological studies examining associations between objectively measured air pollution and chronic bronchitis symptoms in adults ${ }^{10-27}$ are difficult to compare. For example, some studies have used surrogate measures for air pollution (eg, distance from the main road, ${ }^{13} 202127$ traffic intensity ${ }^{17}$ ), others used air pollution data from local monitoring

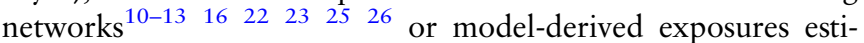
mated at home address. ${ }^{15} \quad 17 \quad 1924$ Some $^{13} \quad 15 \quad 17$ but not

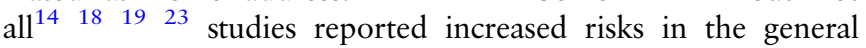
population, whereas studies in specific populations reported associations only in never-smokers ${ }^{10-12} 1626$ or females. ${ }^{20} 2125$

The present study investigates cross-sectional associations between ambient air pollution estimated at home address and prevalence of chronic bronchitis symptoms in five European cohort studies participating in European Study of Cohorts for Air Pollution Effects (ESCAPE) project. Taking advantage of individual information and repeated assessments, we gave special attention to the time period of exposure (contemporary, historic 2000s and historic 1990s exposures) in repeated crosssectional analyses and conducted extensive sensitivity analyses.

\section{METHODS}

\section{Study populations}

Analyses were based on subpopulations from the European Community Respiratory Health Survey (ECRHS); National Survey of Health and Development (NSHD) from the UK; the Study on the influence of Air pollution on Lung function, Inflammation and Aging (SALIA) from Ruhr area in Germany; the Swiss cohort study on Air Pollution And Lung and heart Diseases in Adults (SAPALDIA); and the French Asthma-E3N study, an asthma case-control study nested in the 'Etude Épidémiologique de Femmes de la Mutuelle Générale de l'Education Nationale (E3N)' cohort who were living in geographic areas covered by ESCAPE exposure models ('ESCAPE areas'). A brief description of each cohort is available in online supplements-1. Those included in the analyses had valid chronic bronchitis data and information on sex, age, smoking status, season of questionnaire interview, education. The NSHD, SALIA and SAPALDIA contributed information from two assessment rounds. Ethical approvals for analyses were obtained for all cohorts.

\section{Outcome definition}

Chronic bronchitis symptoms were assessed by questionnaire in all cohorts using standard questions based on those defined by the British Medical Research Council (MRC) in $1965,{ }^{1}$ as reported cough and phlegm production first thing in the morning and/or during the day or at night for 3 months of the year for $\geq 2$ years. Other outcomes investigated were chronic cough (reported cough for 3 months for $\geq 2$ years regardless of reported phlegm or not) and chronic phlegm (reported phlegm for 3 months for $\geq 2$ years regardless of reported cough or not), except for SALIA, where questions regarding phlegm production were not asked separately from cough, therefore it was not possible to derive the outcome of 'chronic phlegm' (online supplements-2).

\section{Exposure measurements}

ESCAPE-period exposures

The ESCAPE exposure assessments have been described elsewhere. $^{28}{ }^{29}$ Briefly, a standardised protocol was applied in all geographic sites within the ESCAPE areas during October 2008 to April 2011. Nitrogen dioxide $\left(\mathrm{NO}_{2}\right)$ and nitrogen oxides $\left(\mathrm{NO}_{\mathrm{x}}\right)$ measurements were conducted in 36 ESCAPE study areas while PM $\left(\mathrm{PM}_{10}, \mathrm{PM}\right.$ with aerodynamic diameter $\leq 10 \mu \mathrm{m}$ and $\mathrm{PM}_{2.5}$, PM with aerodynamic diameter $\leq 2.5 \mu \mathrm{m}$ ) were measured in 20 ESCAPE study areas, both in a 14-day period of each of three seasons (cold, warm and intermediate). Annual average concentrations for each monitoring site were calculated by combining the three 14-day periods with measurement data from a centrally located reference site, in operation during the whole study period, to adjust for temporal variability. The land-use regression (LUR) model developed used geographic information system (GIS)-derived predictor variables to describe spatial variation of annual average concentrations for each study area at measurement locations. An annual average estimate was then assigned from the LUR models to each geocoded address (place of residence) based on the date of questionnaire assessment for study participants. In addition, two indicators of local exposures to traffic were derived for each participant's address: traffic intensity on the nearest road (traffic intensity, vehicles/ day) and total traffic load on major roads in a $100 \mathrm{~m}$ buffer (traffic load, vehicles*m/day).

Each participant was assigned an annual average concentration at home outdoor of $\mathrm{NO}_{2}, \mathrm{NO}_{\mathrm{x}}$ and the background levels of $\mathrm{NO}_{2}$. For participants residing within ESCAPE areas with PM measurements, they were also assigned exposures to $\mathrm{PM}_{2.5}$, $\mathrm{PM}_{10}$, the coarse fraction of $\mathrm{PM}\left(\mathrm{PM}_{\text {coarse }}\right.$ as $\mathrm{PM}_{10}$ minus $\left.\mathrm{PM}_{2.5}\right)$ and $\mathrm{PM}_{2.5 \text { abs }}$, the light absorbance of $\mathrm{PM}_{2.5}$ (similar to black carbon').

\section{Back-extrapolation}

Questionnaire assessments in some cohorts occurred prior to the ESCAPE monitoring campaign in 2008-2011, with some up to 25 years earlier. Due to changes (usually decreases) in air pollution over time, ESCAPE-period exposure values were backextrapolated to the years of collection of health data assuming proportional changes in within-city spatial patterns. Here, individually assigned estimates of ambient concentrations were adjusted (calibrated) for the long-term trends using a predefined backextrapolation algorithm (see http://www.escapeproject.eu/manuals/ Procedure_for_extrapolation_back_in_time.pdf; accessed 10 May 2014).

Back-extrapolation for $\mathrm{NO}_{2}$ and $\mathrm{PM}_{10}$ was conducted by ratio methods to the most recent follow-up years in ECRHS and SAPALDIA (assessments in 1998-2002 and 2002, respectively) and also to earlier assessment in SALIA in 1985-1994, NSHD in 1999 and SAPALDIA in 1991.

\section{Statistical analyses}

Each cohort was first analysed separately using centrally written analytic codes, and harmonised outcome and confounder variables. Descriptive analyses were conducted including Spearman correlation coefficients. The analytic strategy, including all models, sensitivity and subgroup analyses, was specified a priori, 
based on current knowledge. Cross-sectional analyses using logistic regression models were undertaken to obtain cohortspecific ORs. Results were then combined using both fixed effects and random effects meta-analyses; pooled estimates from the latter were only shown when heterogeneity $(\mathrm{p}<0.05)$ existed across cohorts.

The main analyses used 'ESCAPE-period exposure' for 20082011 applied to the most recent assessment within 10 years of exposure models in all five cohorts (earliest ECRHS and SAPALDIA with assessments in 2002).

A sequence of nested models were run for each outcome: model 1-unadjusted crude model; model 2-adjustments of age and sex; model 3 (main model)-further adjusted for smoking, education level and interview season, all uniformly defined in all cohorts. Model 4 was further adjusted for environmental tobacco smoking (ETS) exposures at home and/or at work and occupational exposures to any of vapours/gases/dusts/ fumes (VGDF); availability and definition of these differed across cohorts. Model 5 was a study-specific model further adjusted for smoking pack years and locally defined neighbourhood-level socioeconomic status. All traffic indicator models were adjusted for the background $\mathrm{NO}_{2}\left(\mathrm{NO}_{2}\right.$ not directly influenced by traffic) to better estimate near traffic effects.

In main analyses, based on model 3 using ESCAPE-period exposures, cohort-specific sensitivity analyses were conducted (i) on the following potentially sensitive subgroups: females, asthmatics, those aged $\geq 50$ years and never-smokers; (ii) excluding those with COPD and/or asthma.

All cohort-specific results from model 3 (or where appropriate, related subgroup and/or sensitivity analyses), were then combined using both fixed effects and random effect meta-analyses by the Stata metan command; pooled estimates from the latter were only shown when heterogeneity $(p<0.05)$ existed across cohorts. Results presented/used in the meta-analyses for multicountry study ECRHS were from random effect models with city modelled as a random effect while the other four were from fixed effect models with country/area modelled as a fixed effect.

Further sensitivity analyses were conducted to address issues relating to cohort heterogeneity and exposure estimation. In main analyses, based on model 3 using ESCAPE-period exposures, cohort heterogeneity was investigated in leave-one-out meta-analyses, where each cohort was dropped in turn. To investigate exposure issues, we (i) conducted meta-analyses excluding centres with poorer exposure model validation statistics $\left(\mathrm{R}^{2}<0.6\right)$; (ii) restricted analyses to non-movers (those who did not move between the most recent and previous assessment, which were at least 8 years apart); (iii) conducted analyses using 'contemporary exposure estimates'; these used ESCAPE 20082011 estimates for Asthma-E3N (2011), NSHD (2008) and SALIA (2006/2010), that is, excluding SAPALDIA and ECHRHS where questionnaire assessments were $>6$ years prior to exposure estimation; (iv) conducted analyses using 'historic exposure estimates' back-extrapolated to year of assessment for assessments in 1999-2002 (ECRHS 2002, NSHD 1999, SAPALDIA 2002) and in the early 1990s (SAPALDIA 1991, SALIA 1985-1994), that is, when exposures were higher.

Statistical analyses were performed using Stata V.12.0, Texas, USA. Statistical significance was set at $\mathrm{p}$ value $<0.05$.

\section{RESULTS}

For main analyses using ESCAPE-period estimates for the most recent assessment, there were 15279 participants successfully assigned at least $\mathrm{NO}_{2}$ estimates (table 1) and 10537 participants assigned at least $\mathrm{PM}_{10}$ estimates (see online supplements-3) with information on variables of main model 3. At the most recent assessment, mean age of the study population ranged from 42.9 years (ECRHS) to 71.5 years (SALIA). Asthma-E3N and SALIA were cohorts of older females only. Current smokers ranged from $5.3 \%$ (SALIA) to $32 \%$ in the younger general population of ECRHS. Asthma-E3N participants were mainly teachers, and $91.3 \%$ were highly educated compared with $11.5 \%$ in NSHD. VGDF exposure was $30-40 \%$ in the mixed sex general population cohorts (ECRHS, NSHD, SAPALDIA) but lower in the female cohorts. Prevalence of chronic bronchitis ranged from 1.5\% (Asthma-E3N) to 6.8\% (SALIA) (see online supplements-4).

Summary statistics of ESCAPE-period air pollutants and traffic indicators are presented in online supplements-5. Mean $\mathrm{NO}_{2}$ ranged from $22 \mu \mathrm{g} / \mathrm{m}^{3}$ (NSHD) to $31 \mu \mathrm{g} / \mathrm{m}^{3}$ (Asthma-E3N), whereas mean $\mathrm{PM}_{10}$ ranged from $16 \mu \mathrm{g} / \mathrm{m}^{3}$ (NSHD) to $27 \mu \mathrm{g} / \mathrm{m}^{3}$ (SALIA). Within-study contrasts assessed by IQR varied from $8 \mu \mathrm{g} / \mathrm{m}^{3}$ in SAPALDIA to $20 \mu \mathrm{g} / \mathrm{m}^{3}$ in ECRHS for $\mathrm{NO}_{2}$ and $2 \mu \mathrm{g} / \mathrm{m}^{3}$ (NSHD) to $9.2 \mu \mathrm{g} / \mathrm{m}^{3}$ (ECRHS) for $\mathrm{PM}_{10}$. Exposures back-extrapolated to the 1990s were higher than for estimates at later assessments.

Spearman correlation coefficients between $\mathrm{PM}$ and $\mathrm{NO}_{\mathrm{x}} / \mathrm{NO}_{2}$ metrics were high $(\mathrm{r} \sim 0.7-0.8)$, therefore precluding two pollutant analyses, while correlations between pollutants and traffic measures were low to moderate $(\mathrm{r} \sim 0.3-0.5)$ (see online supplements-6).

ESCAPE-period exposure estimates 2008-2011 were highly correlated $(r>0.9)$ with exposures back-extrapolated to the assessments in 2002 ECRHS and SAPALDIA, justifying the use of ESCAPE-period exposures in main analyses.

\section{Results from analyses using ESCAPE-period exposure estimates}

Combined estimates from the meta-analyses using model 3 are displayed in table 2 (see also figure 1 and Forest plots, online supplements-7). No statistically significant overall associations were found between any air pollutant or traffic indicator and any outcome using ESCAPE-period estimates.

Associations in meta-analyses using main model 3 leaving out one cohort in turn (online supplements-8) or restricted to cohorts with 'contemporary exposure estimates': Asthma-E3N (2011), NSHD (2008) and SALIA (2006-2010) (online supplements-9) were all null except for associations between chronic cough and $\mathrm{PM}_{2.5 \text { abs }}$ in analyses not including ECRHS, with OR, 95\% CI 1.20 (1.01 to 1.44$)$ per $10^{-5} / \mathrm{m}$.

Further adjustments in models 4 and 5 did not change the results substantially, although effect estimates were slightly smaller and the 95\% CIs became wider (data not shown), which may in part relate to fewer participants.

\section{Sensitive subgroups}

In never-smokers, higher and uniformly positive effect estimates for all air pollutants and traffic indicators for all three outcomes were observed (table 3). A statistically significant association was found between chronic phlegm and both $\mathrm{PM}_{10}(\mathrm{OR}, 95 \% \mathrm{CI}$ 1.32 (1.02 to 1.71 ), per $10 \mu \mathrm{g} / \mathrm{m}^{3}$ increase) and $\mathrm{PM}_{\text {coarse }}(\mathrm{OR}$, $95 \%$ CI 1.31 (1.05 to 1.64 ), per $5 \mu \mathrm{g} / \mathrm{m}^{3}$ increase) (figure 2 ). In analyses of never-smokers in cohorts with 'contemporary exposure estimates' (online supplements-9), associations with chronic phlegm were no longer statistically significant but associations between chronic cough and $\mathrm{PM}_{2.5}$ and $\mathrm{PM}_{2.5 \text { abs }}$ became larger and statistically significant: $\mathrm{PM}_{2.5}$ OR, 95\% CI 1.47 (1.02 to 2.12) per $5 \mu \mathrm{g} / \mathrm{m}^{3}$ increase, $\mathrm{PM}_{2.5 \mathrm{abs}} \mathrm{OR}, 95 \%$ CI 1.30 (1.04 to 
Table 1 Description of study population (subpopulations of the original study with individually assigned $\mathrm{NO}_{2}$ measures) of all five cohorts as used at each assessment

\begin{tabular}{|c|c|c|c|c|c|c|c|c|c|c|c|c|c|c|c|c|}
\hline \multirow[b]{3}{*}{$\begin{array}{l}\text { Study } \\
\text { Co-variables }\end{array}$} & \multirow{2}{*}{\multicolumn{2}{|c|}{$\begin{array}{l}\text { Asthma-E3N } \\
\text { Assessment } \\
2011 \\
\mathrm{~N}=4070\end{array}$}} & \multirow{2}{*}{\multicolumn{2}{|c|}{$\begin{array}{l}\text { ECRHS } \\
\text { Assessment } \\
1998-2002 \\
\mathrm{~N}=5053 \\
\end{array}$}} & \multicolumn{4}{|l|}{ NSHD } & \multicolumn{4}{|l|}{ SALIA } & \multicolumn{4}{|c|}{ SAPALDIA } \\
\hline & & & & & \multicolumn{2}{|c|}{$\begin{array}{l}\text { Assessment } \\
1999 \\
\mathrm{~N}=2322\end{array}$} & \multicolumn{2}{|c|}{$\begin{array}{l}\text { Assessment } \\
2008 \\
N=2024\end{array}$} & \multicolumn{2}{|c|}{$\begin{array}{l}\text { Assessment } \\
1985-1994 \\
\mathrm{~N}=4360\end{array}$} & \multicolumn{2}{|c|}{$\begin{array}{l}\text { Assessment } \\
2006-2010 \\
\mathrm{~N}=2019\end{array}$} & \multicolumn{2}{|c|}{$\begin{array}{l}\text { Assessment } \\
1991 \\
\mathrm{~N}=3766\end{array}$} & \multicolumn{2}{|c|}{$\begin{array}{l}\text { Assessment } \\
2002 \\
N=2113\end{array}$} \\
\hline & $\begin{array}{l}\mathrm{N} / \\
\text { Mean }\end{array}$ & $\begin{array}{l}\% \\
\text { ISD }\end{array}$ & $\begin{array}{l}\mathrm{N} / \\
\text { Mean }\end{array}$ & $\begin{array}{l}\% \\
\text { ISD }\end{array}$ & $\begin{array}{l}\mathrm{N} / \\
\text { Mean }\end{array}$ & $\begin{array}{l}\% \\
\text { ISD }\end{array}$ & $\begin{array}{l}\mathrm{N} / \\
\text { Mean }\end{array}$ & $\begin{array}{l}\% \\
\text { ISD }\end{array}$ & $\begin{array}{l}\mathrm{N} / \\
\text { Mean }\end{array}$ & $\begin{array}{l}\% \\
\text { ISD }\end{array}$ & $\begin{array}{l}\mathrm{N} / \\
\text { Mean }\end{array}$ & $\begin{array}{l}\% \\
\text { ISD }\end{array}$ & $\begin{array}{l}\mathrm{N} / \\
\text { Mean }\end{array}$ & $\begin{array}{l}\% \\
\text { ISD }\end{array}$ & $\begin{array}{l}\mathrm{N} / \\
\text { Mean }\end{array}$ & $\begin{array}{l}\% \\
\text { ISD }\end{array}$ \\
\hline Female & 4070 & $100 \%$ & 2712 & $53.7 \%$ & 1216 & $52.4 \%$ & 1075 & $53.1 \%$ & 4360 & $100 \%$ & 2019 & $100 \%$ & 1949 & $51.8 \%$ & 1126 & $53.3 \%$ \\
\hline Age, years & 70.0 & 6.4 & 42.9 & 7.1 & 53.5 & 0.2 & 61.9 & 0.6 & 54.5 & 0.6 & 71.5 & 3.4 & 41.3 & 11.8 & 53.1 & 11.5 \\
\hline $\begin{array}{l}\text { Body mass index } \\
\text { (BMI), } \mathrm{kg} / \mathrm{m}^{2}\end{array}$ & 24.0 & 4.5 & 25.7 & 4.6 & 27.4 & 4.7 & 27.9 & 4.9 & 27.6 & 4.7 & 26.9 & 4.3 & 23.7 & 3.9 & 25.5 & 4.3 \\
\hline $\begin{array}{l}\text { Smoking pack } \\
\text { years* }\end{array}$ & 3.5 & 10.2 & 12.2 & 18.2 & 10.3 & 13.6 & 10.7 & 15.2 & 4.1 & 10.3 & 4.3 & 11.9 & 11.8 & 19.0 & 13.8 & 22.4 \\
\hline Never-smoker & 2770 & $68.0 \%$ & 2086 & $41.3 \%$ & 708 & $30.5 \%$ & 644 & $31.8 \%$ & 3230 & $74.1 \%$ & 1607 & $79.6 \%$ & 1571 & $41.7 \%$ & 853 & $40.4 \%$ \\
\hline Ex-smoker & 1041 & $25.6 \%$ & 1364 & $27.0 \%$ & 1133 & $48.8 \%$ & 1141 & $56.4 \%$ & 378 & $8.7 \%$ & 304 & $15.1 \%$ & 809 & $21.5 \%$ & 678 & $32.1 \%$ \\
\hline Current smoker & 259 & $6.4 \%$ & 1603 & $31.7 \%$ & 481 & $20.7 \%$ & 239 & $11.8 \%$ & 752 & $17.2 \%$ & 108 & $5.3 \%$ & 1386 & $36.8 \%$ & 582 & $27.5 \%$ \\
\hline Low education & 107 & $2.6 \%$ & 1471 & $29.1 \%$ & 965 & $41.6 \%$ & 798 & $39.4 \%$ & 1260 & $28.9 \%$ & 438 & $21.7 \%$ & 574 & $15.2 \%$ & 137 & $6.5 \%$ \\
\hline $\begin{array}{l}\text { Medium } \\
\text { education }\end{array}$ & 246 & $6.1 \%$ & 1732 & $34.3 \%$ & 1105 & $47.6 \%$ & 994 & $49.1 \%$ & 2100 & $48.2 \%$ & 986 & $48.8 \%$ & 2410 & $64.0 \%$ & 1352 & $64.0 \%$ \\
\hline High education & 3717 & $91.3 \%$ & 1850 & $36.6 \%$ & 252 & $10.9 \%$ & 232 & $11.5 \%$ & 1000 & $22.9 \%$ & 595 & $29.5 \%$ & 782 & $20.8 \%$ & 624 & $29.5 \%$ \\
\hline ETS exposures & 168 & $5.1 \%$ & 506 & $10.0 \%$ & 523 & $25.0 \%$ & 452 & $24.6 \%$ & 2205 & $50.9 \%$ & 976 & $49.2 \%$ & 518 & $13.8 \%$ & 146 & $6.9 \%$ \\
\hline VGDF exposures & 879 & $23.2 \%$ & 2146 & $44.4 \%$ & 721 & $35.1 \%$ & 632 & $34.8 \%$ & 428 & $9.8 \%$ & 184 & $9.1 \%$ & 1060 & $28.2 \%$ & 581 & $27.5 \%$ \\
\hline Asthmatics† & 967 & $26.6 \%$ & 782 & $15.5 \%$ & 221 & $10.0 \%$ & 192 & $9.8 \%$ & 102 & $2.4 \%$ & 121 & $6.4 \%$ & 296 & $7.9 \%$ & 181 & $8.6 \%$ \\
\hline $\begin{array}{l}\text { COPD Gold stage } \\
1 \text { plus } \ddagger\end{array}$ & $\mathrm{n} / \mathrm{a}$ & $\mathrm{n} / \mathrm{a}$ & 305 & $7.2 \%$ & 110 & $6.6 \%$ & 92 & $8.2 \%$ & 289 & $12.5 \%$ & 102 & $15.4 \%$ & 395 & $11.4 \%$ & 399 & $20.6 \%$ \\
\hline
\end{tabular}

Table shows the $\mathrm{N}$ (and \% of $\mathrm{N}$ ) for categorical variables and mean (SD) for continuous variables.

${ }^{*}$ Calculations based on ex-smokers and current smokers.

†Asthmatics cases were defined as those who answered 'yes' to ever-asthma questions in the questionnaires of all cohorts.

¥Stages of COPD were classified according to the GOLD (Global Initiative for Chronic Obstructive Lung Disease) definitions and NHANES III (Third National Health and Nutrition

Examination Survey) reference equations. There were no lung function test conducted in Asthma-E3N cohort hence results were n/a (not applicable). Only pre-bronchodilator spirometric measurements were available for all cohorts.

ECRHS, European Community Respiratory Health Survey; ETS, Environmental Tobacco Smoke at home and/or at work; NSHD, National Survey of Health and Development; SALIA, Study on the influence of Air pollution on Lung function, Inflammation and Aging; SAPALDIA, Swiss cohort study on Air Pollution And Lung and heart Diseases in Adults; VGDF, occupational vapour/gases/dust/fumes exposure (any of).

Table 2 Overall populations at the most recent assessment *: fixed-effect meta-analysis results on model 3 (adjusted for age, sex, smoking, education and season of interview) for all air pollutants and traffic indicators for each outcome, using ESCAPE-period (2008-2011) exposures from all five cohorts.

\begin{tabular}{|c|c|c|c|c|c|c|}
\hline \multirow{2}{*}{$\begin{array}{l}\text { Outcome } \\
\text { Exposuret }\end{array}$} & \multicolumn{2}{|c|}{ Chronic bronchitis } & \multicolumn{2}{|l|}{ Chronic cough } & \multicolumn{2}{|c|}{ Chronic phlegm } \\
\hline & $\begin{array}{l}\text { OR } \\
(95 \% \mathrm{Cl})\end{array}$ & $p_{\text {het }} \ddagger$ & $\begin{array}{l}\text { OR } \\
(95 \% \mathrm{CI})\end{array}$ & Phet $_{\text {h }}$ & $\begin{array}{l}\text { OR } \\
(95 \% \mathrm{Cl})\end{array}$ & Phet $_{\text {het }}$ \\
\hline $\mathrm{PM}_{2.5}\left(5 \mu \mathrm{g} / \mathrm{m}^{3}\right)$ & $\begin{array}{l}0.90 \\
(0.74 \text { to } 1.09)\end{array}$ & 0.754 & $\begin{array}{l}0.91 \\
(0.80 \text { to } 1.04)\end{array}$ & 0.440 & $\begin{array}{l}0.96 \\
(0.84 \text { to } 1.11)\end{array}$ & 0.850 \\
\hline $\mathrm{PM}_{2.5 \text { abs }}\left(\right.$ per $10^{-5} \mathrm{~m}^{-1}$ ) & $\begin{array}{l}1.02 \\
(0.85 \text { to } 1.22)\end{array}$ & 0.504 & $\begin{array}{l}1.01 \\
(0.89 \text { to } 1.15)\end{array}$ & 0.070 & $\begin{array}{l}1.02 \\
(0.88 \text { to } 1.18)\end{array}$ & 0.693 \\
\hline $\mathrm{PM}_{10}\left(10 \mu \mathrm{g} / \mathrm{m}^{3}\right)$ & $\begin{array}{l}0.92 \\
(0.75 \text { to } 1.13)\end{array}$ & 0.193 & $\begin{array}{l}0.92 \\
(0.80 \text { to } 1.06)\end{array}$ & 0.494 & $\begin{array}{l}1.02 \\
(0.87 \text { to } 1.18)\end{array}$ & 0.696 \\
\hline $\mathrm{PM}_{\text {coarse }}\left(5 \mu \mathrm{g} / \mathrm{m}^{3}\right)$ & $\begin{array}{l}0.99 \\
(0.83 \text { to } 1.18)\end{array}$ & 0.165 & $\begin{array}{l}0.99 \\
(0.87 \text { to } 1.12)\end{array}$ & 0.737 & $\begin{array}{l}1.07 \\
(0.94 \text { to } 1.22)\end{array}$ & 0.131 \\
\hline $\mathrm{NO}_{2}\left(10 \mu \mathrm{g} / \mathrm{m}^{3}\right)$ & $\begin{array}{l}1.00 \\
(0.92 \text { to } 1.08)\end{array}$ & 0.973 & $\begin{array}{l}1.05 \\
(0.99 \text { to } 1.11)\end{array}$ & 0.953 & $\begin{array}{l}1.01 \\
(0.95 \text { to } 1.07)\end{array}$ & 0.656 \\
\hline $\mathrm{NO}_{\mathrm{x}}\left(20 \mu \mathrm{g} / \mathrm{m}^{3}\right)$ & $\begin{array}{l}1.02 \\
(0.94 \text { to } 1.09)\end{array}$ & 0.793 & $\begin{array}{l}1.04 \\
(0.98 \text { to } 1.09)\end{array}$ & 0.622 & $\begin{array}{l}1.02 \\
(0.96 \text { to } 1.08)\end{array}$ & 0.393 \\
\hline Traffic intensity§ & $\begin{array}{l}0.95 \\
(0.75 \text { to } 1.19)\end{array}$ & 0.739 & $\begin{array}{l}0.96 \\
(0.80 \text { to } 1.14)\end{array}$ & 0.339 & $\begin{array}{l}0.98 \\
(0.82 \text { to } 1.17)\end{array}$ & 0.366 \\
\hline Traffic loadף & $\begin{array}{l}0.99 \\
(0.82 \text { to } 1.20)\end{array}$ & 0.509 & $\begin{array}{l}0.95 \\
(0.81 \text { to } 1.10)\end{array}$ & 0.831 & $\begin{array}{l}0.97 \\
(0.83 \text { to } 1.13)\end{array}$ & 0.797 \\
\hline
\end{tabular}

${ }^{*}$ Asthma-E3N 2011, ECRHS 1998-2002, NSHD 2008, SALIA 2006-10, SAPALDIA 2002. Due to questionnaire wording SALIA is not included in analyses of phlegm alone.

tResults were interpreted as per exposure unit, as shown in the parentheses.

$\neq p_{\text {het }}: p$ value for heterogeneity.

$\S$ Binary variable, $<5000$ (reference group) vs $>5000$ vehs/day.

१Binary variable, $<500000$ (reference group) vs $>500000$ vehs $\mathrm{m} /$ day.

ECRHS, European Community Respiratory Health Survey; ESCAPE, European Study of Cohorts for Air Pollution Effects; NO; nitrogen oxides; NSHD, National Survey of Health and

Development; PM, particulate matter; SALIA, Study on the influence of Air pollution on Lung function, Inflammation and Aging; SAPALDIA, Swiss cohort study on Air Pollution And

Lung and heart Diseases in Adults. 


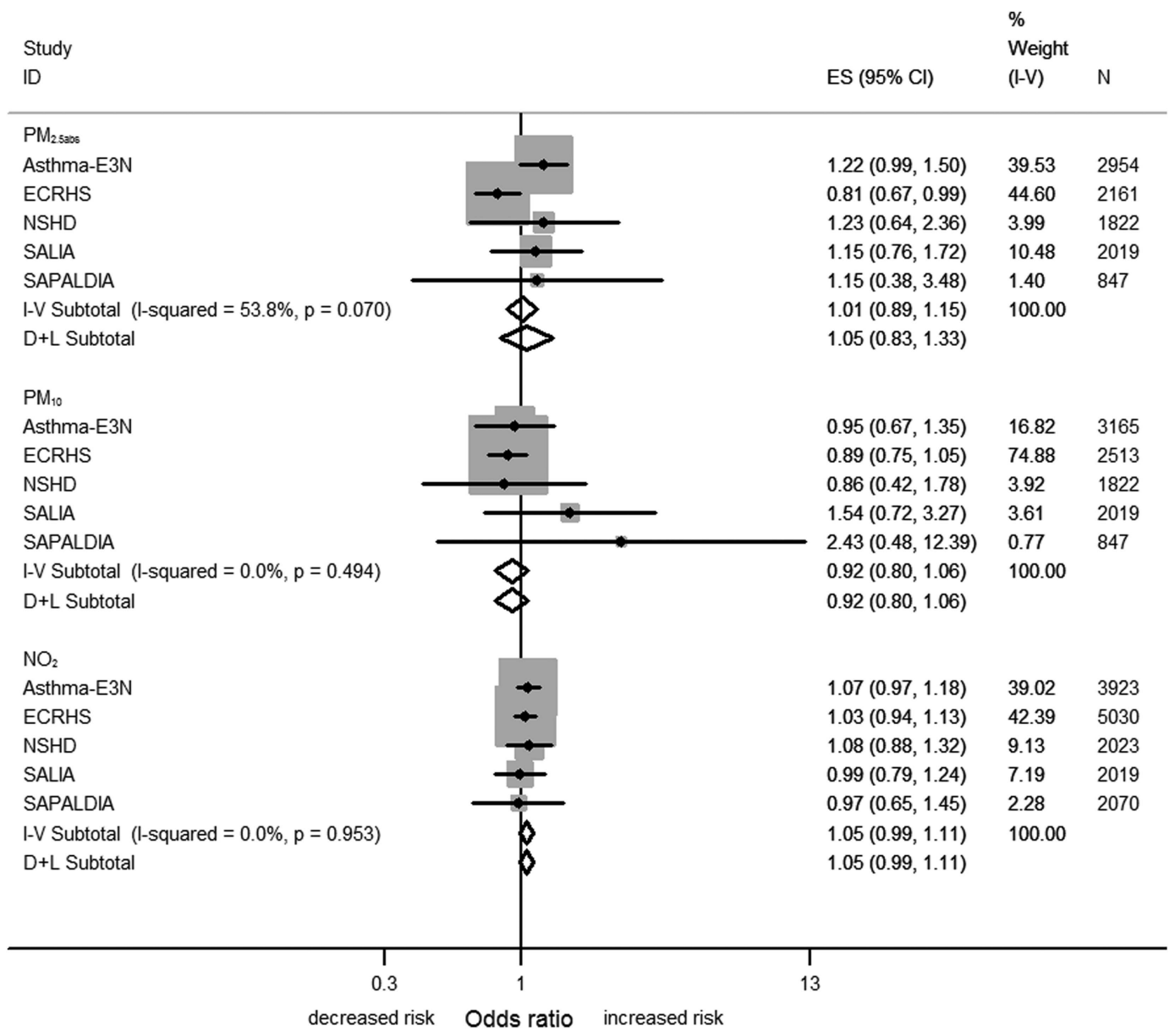

Figure 1 Meta-analysis results on model 3 (adjusted for age, sex, smoking, education, season of questionnaire interview) for $\mathrm{NO}_{2}\left(\right.$ per $10 \mu \mathrm{g} / \mathrm{m}^{3}$ ), $\mathrm{PM}_{10}$ (per $10 \mu \mathrm{g} / \mathrm{m}^{3}$ ) and $\mathrm{PM}_{2.5 \text { abs }}$ (per $10^{-5} \mathrm{~m}^{-1}$ ) for chronic cough at the most recent assessment using the European Study of Cohorts for Air Pollution Effects (ESCAPE)-period exposures in the overall populations from all five cohorts. I-squared, variation in estimated effect attributable to heterogeneity; I-V, inverse-variance weighted fixed effects method; D-L, DerSimonian-Laird random effects method; ES, effect estimate; PM, particulate matter.

1.63) per $10^{-5} / \mathrm{m}$, although with evidence of heterogeneity for the latter $\left(\mathrm{P}_{\text {het }}=0.024\right)$. In the random-effects analysis, the $\mathrm{PM}_{2.5 \text { abs }}$ result was not statistically significant: OR, 95\% CI $1.58(0.90$ to 2.76$)$ per $10^{-5} / \mathrm{m}$.

There were no statistically significant effect estimates observed in meta-analyses for asthmatics, females, participants aged 50+ years, participants without COPD and/or asthma or non-movers (results not shown).

\section{Exposure-related sensitivity analyses}

Sensitivity analyses for $\mathrm{NO}_{2}$ and $\mathrm{NO}_{\mathrm{x}}$ excluding centres with LUR model validation $\mathrm{R}^{2}$ statistics $<0.6$ gave similar null results for the main ESCAPE-period analyses (online supplements-10). The $\mathrm{R}^{2}$ statistics were all $>0.6$ for PM estimates in our study areas.

Using back-extrapolated 'historic exposure estimates' to 1999-2002 (table 4), there were consistent but statistically nonsignificant elevated risks in all populations but not in neversmokers for all three outcomes with $\mathrm{NO}_{2}$ and $\mathrm{PM}_{10}$. Using historic exposure estimates to the early 1990s in only two cohorts (table 5), statistically significant associations were found between $\mathrm{NO}_{2}$ and both chronic bronchitis (OR: 1.10, 95\% CI 1.00 to 1.22 ) and chronic cough (OR: $1.10,95 \%$ CI 1.01 to 1.20$)$.

\section{DISCUSSION}

This is one of the largest studies to investigate the link between bronchitis symptoms and current air pollution exposures using five cohorts in nine European countries. Main analyses defined a priori did not show significant associations between the period prevalence of chronic bronchitis, cough or phlegm and any of six air pollutant metrics and two traffic indicators. Associations between the particulate measure of black carbon $\mathrm{PM}_{2.5 \mathrm{abs}}$ and chronic cough were statistically significant if leaving out a younger cohort (ECRHS) in analyses of all individuals and of never-smokers. In never-smokers, associations were in general larger and consistently positive, reaching statistical significance between phlegm and $\mathrm{PM}_{\text {coarse }}$ (but not $\mathrm{PM}_{2.5}$ ). The higher $\mathrm{NO}_{2}$ exposures in the early 1990s were associated with chronic bronchitis and cough, but this analysis was only possible for two cohorts.

\section{Findings in comparisons with previous studies}

To our knowledge, this is one of the first epidemiological studies to report on long-term associations between the coarse fraction of ambient particles and cough and phlegm in adults. $\mathrm{PM}_{\text {coarse }}$ has previously been found to be associated with respiratory hospital admissions ${ }^{30}$ and to be more potent than fine PM in inducing inflammatory responses in in vitro and in vivo (mouse) studies. ${ }^{31} 32$

We also observed significant associations between $\mathrm{PM}_{10}$ and phlegm in never-smokers but not overall. As in this analysis, cross-sectional associations with chronic bronchitis and with phlegm were seen in never-smokers (but not in former and 
Table 3 Never-smokers at the most recent assessment*: fixed-effect meta-analysis results on model 3 (adjusted for age, sex, smoking, education and season of interview) for all air pollutants and traffic indicators for each outcome, using ESCAPE-period (2008-2011) exposures from all five cohorts

\begin{tabular}{|c|c|c|c|c|c|c|}
\hline \multirow{2}{*}{$\begin{array}{l}\text { Outcome } \\
\text { Exposure‡ }\end{array}$} & \multicolumn{2}{|c|}{ Chronic bronchitis } & \multicolumn{2}{|l|}{ Chronic cough } & \multicolumn{2}{|c|}{ Chronic phlegm } \\
\hline & $\begin{array}{l}\text { OR } \\
(95 \% \mathrm{Cl})\end{array}$ & $p_{\text {het }} \S$ & $\begin{array}{l}\text { OR } \\
(95 \% \mathrm{Cl})\end{array}$ & $p_{\text {het }}$ & $\begin{array}{l}\text { OR } \\
(95 \% \mathrm{CI})\end{array}$ & Phet $_{\text {h }}$ \\
\hline \multirow[t]{2}{*}{$\mathrm{PM}_{2.5}\left(5 \mu \mathrm{g} / \mathrm{m}^{3}\right)$} & 1.28 & 0.488 & 1.11 & 0.091 & 1.16 & 0.519 \\
\hline & (0.95 to 1.72$)$ & & (0.90 to 1.36$)$ & & (0.91 to 1.48$)$ & \\
\hline \multirow{3}{*}{$\mathrm{PM}_{2.5 \mathrm{abs}}\left(\right.$ per $10^{-5} \mathrm{~m}^{-1}$ ) } & 1.20 & 0.233 & 1.16 & 0.032 & 1.10 & 0.602 \\
\hline & (0.92 to 1.57$)$ & & (0.96 to 1.39$)$ & & (0.87 to 1.39$)$ & \\
\hline & & & $1.27 \dagger(0.88$ to 1.85$)$ & & & \\
\hline \multirow[t]{2}{*}{$\mathrm{PM}_{10}\left(10 \mu \mathrm{g} / \mathrm{m}^{3}\right)$} & 1.35 & 0.763 & 1.08 & 0.535 & 1.32 & 0.474 \\
\hline & (0.97 to 1.88$)$ & & (0.86 to 1.35$)$ & & (1.02 to 1.71$)$ & \\
\hline \multirow[t]{2}{*}{$\mathrm{PM}_{\text {coarse }}\left(5 \mu \mathrm{g} / \mathrm{m}^{3}\right)$} & 1.15 & 0.979 & 1.06 & 0.954 & 1.31 & 0.457 \\
\hline & (0.87 to 1.53$)$ & & (0.87 to 1.29$)$ & & (1.05 to 1.64$)$ & \\
\hline \multirow[t]{2}{*}{$\mathrm{NO}_{2}\left(10 \mu \mathrm{g} / \mathrm{m}^{3}\right)$} & 1.06 & 0.440 & 1.04 & 0.088 & 1.02 & 0.234 \\
\hline & (0.93 to 1.20$)$ & & (0.97 to 1.12$)$ & & (0.92 to 1.13$)$ & \\
\hline \multirow[t]{3}{*}{$\mathrm{NO}_{\mathrm{x}}\left(20 \mu \mathrm{g} / \mathrm{m}^{3}\right)$} & 1.09 & 0.151 & 1.04 & 0.021 & 1.05 & 0.121 \\
\hline & (0.93 to 1.28$)$ & & (0.97 to 1.12$)$ & & (0.96 to 1.15$)$ & \\
\hline & & & $1.06+(0.91$ to 1.23$)$ & & & \\
\hline \multirow[t]{2}{*}{ Traffic intensity9 } & 1.12 & 0.763 & 1.07 & 0.629 & 1.04 & 0.830 \\
\hline & (0.79 to 1.57$)$ & & (0.84 to 1.37$)$ & & (0.80 to 1.37$)$ & \\
\hline Traffic load** & $\begin{array}{l}1.11 \\
(0.83 \text { to } 1.49)\end{array}$ & 0.354 & $\begin{array}{l}1.03 \\
(0.82 \text { to } 1.29)\end{array}$ & 0.51 & $\begin{array}{l}1.02 \\
(0.79 \text { to } 1.32)\end{array}$ & 0.422 \\
\hline \multicolumn{7}{|c|}{ 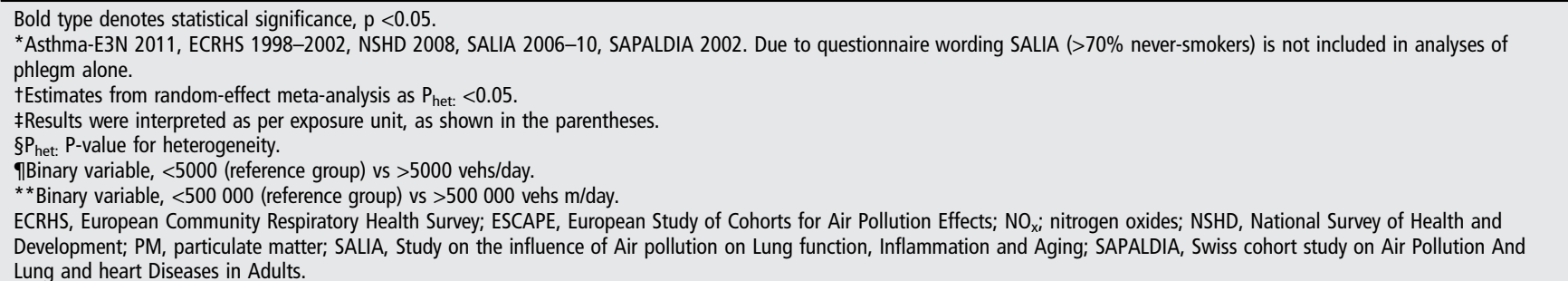 } \\
\hline
\end{tabular}

current smokers) in the SAPALDIA study, ${ }^{26}$ but no statistically significant associations were seen in SALIA (mainly nonsmokers) ${ }^{23}$ while continuous measures of $\mathrm{PM}_{10}$ were not associated with cough in older adults in France. ${ }^{15}$ However, longitudinal analyses in both SALIA ${ }^{22}$ and SAPALDIA ${ }^{24}$ studies suggested declines in $\mathrm{PM}_{10}$ are associated with declines in cough and chronic bronchitis symptoms; additionally, an analysis of Seventh Day Adventist non-smokers found associations between chronic cough and 15 -year cumulative $\mathrm{PM}_{10}$ exposures. ${ }^{10}$

We saw no significant associations overall with $\mathrm{PM}_{2.5}$. This is consistent with previous cross-sectional epidemiological studies in adults in the USA ${ }^{19}$ and a 2006 analysis of the ECRHS ${ }^{25}$ cohort and with a longitudinal analysis in Melbourne ${ }^{14}$ but not an analysis in non-smoking Seventh Day Adventists, which found associations between 20-year cumulative exposure to $\mathrm{PM}_{2.5}$ and chronic bronchitis. ${ }^{11}$ We did observe associations between chronic cough and $\mathrm{PM}_{2.5 \mathrm{abs}}$, a measure of black carbon or soot, in some sensitivity analyses, but these were not consistent and may represent chance findings.

Lack of findings of significant associations with $\mathrm{NO}_{2}$, except for chronic cough and chronic bronchitis in SALIA and SAPALDIA in the 1990s when exposures were higher are partially consistent with previous studies. Significant associations were seen with cough, but not chronic bronchitis in a previous analysis of SALIA $^{23}$; with chronic bronchitis and with phlegm in women but not men in the ECRHS (cough was not considered ${ }^{25}$; with phlegm (but not cough) in women but not men in an older French cohort ${ }^{15}$; and with chronic bronchitis and chronic phlegm in never-smokers in SAPALDIA. ${ }^{26}$ Chronic bronchitis symptoms were not associated with low levels of cumulative $\mathrm{NO}_{2}$ exposure in non-smoking Californians. ${ }^{16}$

We are aware of only one adult study that has considered $\mathrm{NO}_{\mathrm{x}}$ and contrary to our null findings, exposures $>19$ vs $0-8 \mu \mathrm{g} / \mathrm{m}^{3}$ in southern Sweden were associated with higher prevalences of chronic bronchitis. ${ }^{17}$

We found no significant associations of traffic intensity with any chronic bronchitis symptoms, contrary to six previous studies using differing traffic intensity metrics based on traffic counts $^{17} 23$ and distance from road. ${ }^{13} 202127$

ORs using ESCAPE exposure estimates in individual cohorts were comparable with those from previously published analyses using cohort-specific air pollution estimates, allowing for differences in study design (see online supplements-11 for details).

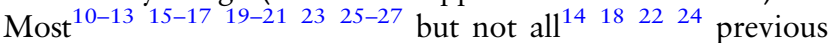
studies examining associations between air pollutant metrics and chronic bronchitis in adults have conducted cross-sectional analyses. We did not do a longitudinal analysis because symptoms come and go over time and they do not represent a stable chronic condition. Also, questionnaire-based reporting is most likely to capture symptoms experienced in the last few months, therefore reflecting cumulative prevalence of acute and subacute effects.

\section{Strengths and weaknesses of the study}

Strengths of this study are the use of five large existing cohorts in different parts of Europe, centrally defined harmonised 


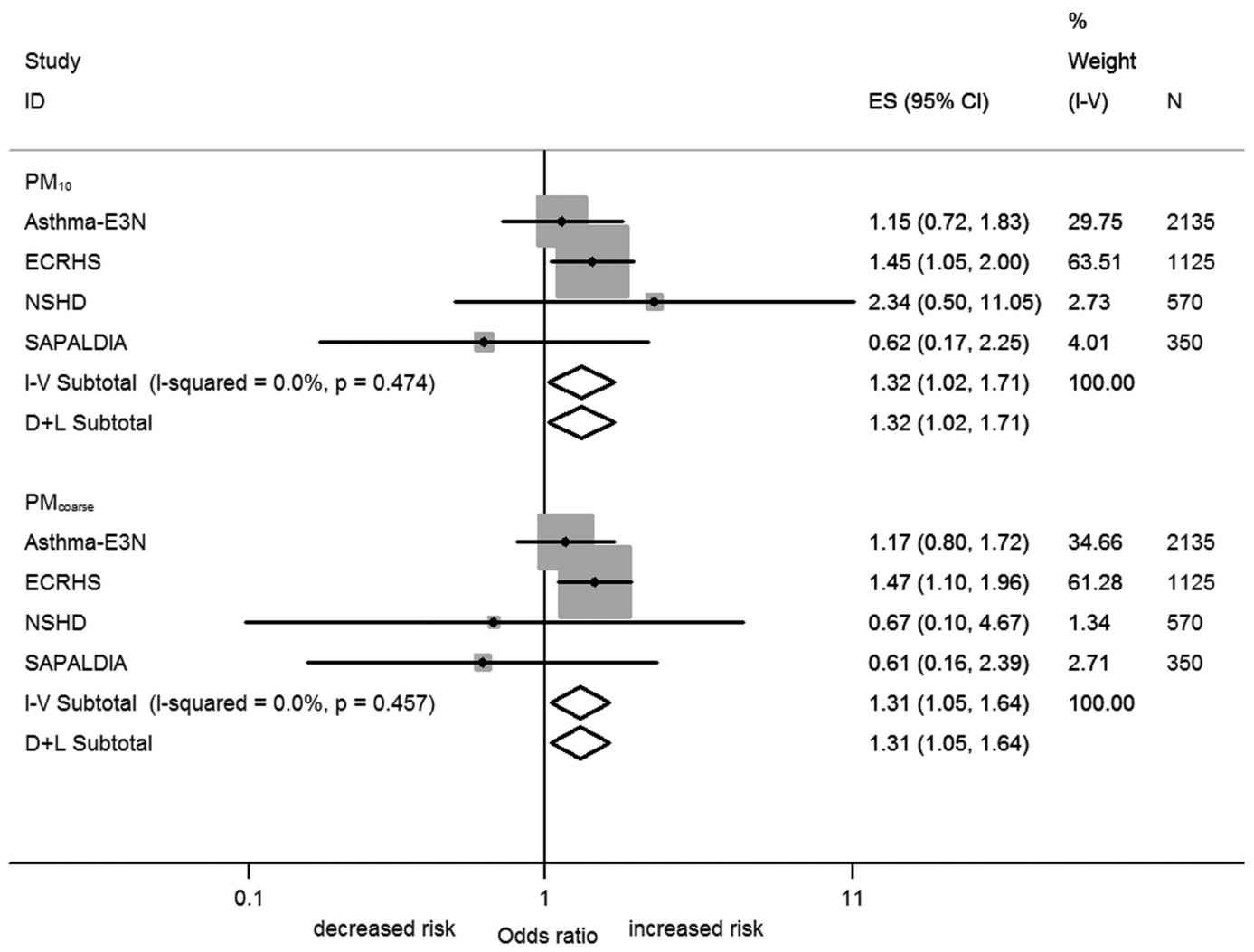

Figure 2 Meta-analysis results on model 3 (adjusted for age, sex, smoking, education, season of questionnaire interview) for $\mathrm{PM}_{10}\left(\mathrm{per} 10 \mu \mathrm{g} / \mathrm{m}^{3}\right.$ ) and $\mathrm{PM}_{\text {coarse }}\left(\right.$ per $5 \mu \mathrm{g} / \mathrm{m}^{3}$ ) for chronic phlegm at the most recent assessment using the European Study of Cohorts for Air Pollution Effects (ESCAPE)-period exposures in the never-smokers populations from four cohorts. I-squared, variation in estimated effect attributable to heterogeneity; I-V, inverse-variance weighted fixed effects method; D-L, DerSimonian-Laird random effects method; PM, particulate matter. The Study on the influence of Air pollution on Lung function, Inflammation and Aging (SALIA) was excluded from the above analysis because questions regarding phlegm production were not asked separately from cough. ES, effect estimate.

variables for each cohort, standard assessment of exposures to eight traffic-related exposures individually assigned to home address and an identical prespecified statistical protocol. However, there were also several limitations. First, uncertainty in exposure estimates might have introduced non-systematic errors, reducing the power of the study to detect effects. However, analyses excluding models with spatial variation $\mathrm{R}^{2}$ $<0.6$ did not substantially change the results (online

Table 4 Back-extrapolated from ESCAPE-period exposures (2008-2011) to early 2000s 'historic exposure estimates': fixed-effect meta-analysis on cross-sectional results from ECRHS (2002), NSHD (1999), SAPALDIA (2002): all participants (upper section) and never-smokers (lower section), main model 3.

\begin{tabular}{|c|c|c|c|c|c|c|c|c|c|c|c|c|}
\hline \multirow[b]{3}{*}{ All participants } & \multicolumn{6}{|c|}{ Back-extrapolated $\mathrm{NO}_{2}, 10 \mu \mathrm{g} / \mathrm{m}^{3}$} & \multicolumn{6}{|c|}{ Back-extrapolated $\mathrm{PM}_{10}, 10 \mu \mathrm{g} / \mathrm{m}^{3}$} \\
\hline & \multicolumn{2}{|c|}{ Chronic bronchitis } & \multicolumn{2}{|c|}{ Chronic cough } & \multicolumn{2}{|c|}{ Chronic phlegm } & \multicolumn{2}{|c|}{ Chronic bronchitis } & \multicolumn{2}{|c|}{ Chronic cough } & \multicolumn{2}{|c|}{ Chronic phlegm } \\
\hline & OR & $95 \% \mathrm{Cl}$ & $\mathrm{OR}$ & $95 \% \mathrm{Cl}$ & OR & $95 \% \mathrm{Cl}$ & OR & $95 \% \mathrm{Cl}$ & OR & $95 \% \mathrm{Cl}$ & OR & $95 \% \mathrm{Cl}$ \\
\hline \multicolumn{13}{|l|}{ Cohort (year) } \\
\hline ECRHS (2002) & 0.99 & (0.90 to 1.10$)$ & 1.03 & (0.96 to 1.11$)$ & 1.01 & (0.94 to 1.09$)$ & 1.22 & (0.83 to 1.80$)$ & 1.03 & (0.80 to 1.34 ) & 1.29 & (0.97 to 1.72$)$ \\
\hline NSHD (1999) & 1.23 & (0.99 to 1.54$)$ & 1.07 & (0.91 to 1.27 ) & 1.16 & (0.96 to 1.41$)$ & 1.20 & (0.57 to 2.53$)$ & 1.05 & (0.61 to 1.79$)$ & 1.39 & (0.74 to 2.61$)$ \\
\hline Phet: & 0.213 & & 0.897 & & 0.350 & & 0.932 & & 0.596 & & 0.420 & \\
\hline \multicolumn{13}{|l|}{ Never-smokers } \\
\hline ECRHS (2002) & 0.99 & (0.79 to 1.23 ) & 1.00 & (0.91 to 1.10 ) & 0.97 & (0.83 to 1.14 ) & 1.92 & (0.92 to 3.99$)$ & 1.17 & (0.74 to 1.84 ) & 1.95 & (1.09 to 3.49 ) \\
\hline NSHD (1999) & 1.04 & $(0.60$ to 1.80$)$ & 0.97 & (0.65 to 1.45 ) & 0.84 & (0.52 to 1.37$)$ & 1.45 & (0.28 to 7.55$)$ & 0.71 & (0.20 to 2.52 ) & 1.00 & (0.24 to 4.21 ) \\
\hline SAPALDIA (2002) & 0.92 & (0.52 to 1.64$)$ & 0.70 & (0.34 to 1.44 ) & 0.88 & (0.67 to 1.16$)$ & 0.65 & (0.10 to 4.37$)$ & 0.59 & (0.07 to 4.96$)$ & 0.77 & (0.35 to 1.70 ) \\
\hline Overall effect & 0.99 & (0.81 to 1.20$)$ & 0.99 & (0.90 to 1.09 ) & 0.94 & (0.83 to 1.07 ) & 1.63 & (0.87 to 3.07 ) & 1.08 & (0.71 to 1.64 ) & 1.37 & (0.88 to 2.13 ) \\
\hline
\end{tabular}


Table 5 Back-extrapolated from ESCAPE-period exposures (2008-11) to early 1990s 'historic exposure estimates': fixed-effect meta-analysis on cross-sectional results from SALIA (1985-1994), SAPALDIA (1991): all participants (upper section) and never-smokers (lower section), main model 3.

\begin{tabular}{|c|c|c|c|c|c|c|c|c|}
\hline \multirow[b]{3}{*}{ All participants } & \multicolumn{4}{|c|}{ Back-extrapolated $\mathrm{NO}_{2}, 10 \mu \mathrm{g} / \mathrm{m}^{3}$} & \multicolumn{4}{|c|}{ Back-extrapolated $\mathrm{PM}_{10}, 10 \mu \mathrm{g} / \mathrm{m}^{3}$} \\
\hline & \multicolumn{2}{|c|}{ Chronic bronchitis } & \multicolumn{2}{|c|}{ Chronic cough } & \multicolumn{2}{|c|}{ Chronic bronchitis } & \multicolumn{2}{|c|}{ Chronic cough } \\
\hline & $\mathrm{OR}$ & $95 \% \mathrm{Cl}$ & $\mathrm{OR}$ & $95 \% \mathrm{Cl}$ & OR & $95 \% \mathrm{Cl}$ & $\mathrm{OR}$ & $95 \% \mathrm{Cl}$ \\
\hline \multicolumn{9}{|l|}{ Cohort (year) } \\
\hline SALIA (1985-94) & 1.08 & (0.96 to 1.21$)$ & 1.08 & $(0.98$ to 1.20$)$ & 1.04 & (0.85 to 1.29$)$ & 1.10 & (0.92 to 1.33$)$ \\
\hline SAPALDIA (1991) & 1.17 & (0.96 to 1.44$)$ & 1.17 & (0.96 to 1.42$)$ & 1.19 & (0.49 to 2.91$)$ & 1.16 & (0.48 to 2.79 ) \\
\hline Overall effect & 1.10 & (1.00 to 1.22$)$ & 1.10 & (1.01 to 1.20$)$ & 1.05 & (0.86 to 1.29$)$ & 1.11 & (0.92 to 1.33$)$ \\
\hline$P_{\text {het }}:$ & 0.474 & & 0.510 & & 0.776 & & 0.909 & \\
\hline \multicolumn{9}{|l|}{ Never-smokers } \\
\hline SALIA (1985-94) & 1.09 & (0.94 to 1.26$)$ & 1.03 & (0.91 to 1.17$)$ & 1.04 & (0.80 to 1.35$)$ & 1.02 & (0.81 to 1.27$)$ \\
\hline SAPALDIA (1991) & 1.24 & (0.85 to 1.79$)$ & 1.25 & (0.86 to 1.80$)$ & 0.90 & (0.19 to 4.30$)$ & 0.81 & (0.17 to 3.77 ) \\
\hline Overall effect & 1.11 & (0.97 to 1.27$)$ & 1.05 & (0.93 to 1.18 ) & 1.04 & (0.80 to 1.34$)$ & 1.01 & (0.81 to 1.26 ) \\
\hline Phet: & 0.538 & & 0.330 & & 0.858 & & 0.774 & \\
\hline
\end{tabular}

Bold type denotes statistical significance, $p<0.05$.

Phet, $\mathrm{p}$ Value for heterogeneity.

Only outcomes available for both SALIA and SAPALDIA are included-analyses of phlegm alone could not be conducted in SALIA due to questionnaire wording.

ESCAPE, European Study of Cohorts for Air Pollution Effects; PM, particulate matter; SALIA, Study on the influence of Air pollution on Lung function, Inflammation and Aging;

SAPALDIA, Swiss cohort study on Air Pollution And Lung and heart Diseases in Adults.

supplements-10 and supplements-12) Second, exposure assessments for ESCAPE occurred years after questionnaire assessments in some cohorts. This was investigated using back-extrapolated exposure assessments aligned with questionnaire. Back-extrapolation assumes within-city spatial contrasts of air pollutants remain similar over long periods of time, for which there is some support from previous studies. ${ }^{33}$ Third, harmonised information on confounders was limited. Fourth, there might be reporting bias, particularly reluctance to report phlegm in females. ${ }^{35}$ Fifth, we conducted many statistical analyses and it is possible that observed associations were due to chance. Sixth, the cohorts were heterogeneous in both design and populations, which may have resulted in systematic differences between studies. To address this, we used harmonised variables, explored potential effect modifiers, used meta-analyses not pooled analyses and conducted leave-one-out sensitivity meta-analyses. Finally, we note that detecting effects in potentially susceptible subgroups, of relevance to environmental policy, may require much larger sample sizes than possible here.

In conclusion, although deleterious effects of ambient air pollution on a range of health outcomes including mortality are well documented, we did not find evidence for significant associations between current long-term average air pollution levels and symptoms of chronic bronchitis, cough or phlegm in $>10000$ European adults. Our study findings, based on very large-scale harmonised population-based cohort studies using a priori specified analyses, contribute to strengthening the evidence-based studies for policy formulation.

\section{Author affiliations}

'Department of Epidemiology \& Biostatistics, MRC-PHE Centre for Environment and Health, School of Public Health, Imperial College London, London, UK

${ }^{2}$ Swiss Tropical and Public Health Institute, Basel, Switzerland

${ }^{3}$ University of Basel, Basel, Switzerland

${ }^{4}$ Leibniz Research Institute for Environmental Medicine (IUF), Düsseldorf, Germany

${ }^{5}$ Centre for Research in Environmental Epidemiology (CREAL), Barcelona, Spain

${ }^{6}$ INSERM, CESP Centre for research in Epidemiology and Population Health, U1018, Respiratory and Environmental epidemiology team, Villejuif, France.

${ }^{7}$ Université Paris Sud 11, UMRS 1018, F-94807, Villejuif, France
${ }^{8}$ Unit of Epidemiology and Medical Statistics, Department of Public Health and Community Medicine, University of Verona, Verona, Italy

${ }^{9}$ Institute for Risk Assessment Sciences, Utrecht University, Utrecht, The Netherlands

${ }^{10} \mathrm{German}$ Research Centre for Environmental Health, Institutes of Epidemiology I and II, Neuherberg, Germany

${ }^{11}$ INSERM, CESP Centre for research in Epidemiology and Population Health, U1018, Nutrition, Hormones, and Women's Health team, Villejuif, France

${ }^{12}$ French Institute for Public Health Surveillance, Saint-Maurice, France

${ }^{13}$ Centre for Environmental Policy, Imperial College London, London, UK

${ }^{14}$ Section of Biostatistics and Clinical Epidemiology, Department of Public Health,

Neuroscience, Experimental and Forensic Medicine, University of Pavia, Pavia, Italy

${ }^{15}$ Department of Public Health and Clinical Medicine, Occupational and

Environmental Medicine, Umea University, Umea, Sweden

${ }^{16}$ Division of Pulmonary Medicine, University Hospitals of Geneva, Geneva, Switzerland

${ }^{17} \mathrm{MRC}$ Unit for Lifelong Health and Ageing at UCL, Institute of Epidemiology and Health Care, University College London, London, UK

${ }^{18}$ Respiratory Epidemiology and Public Health Group, National Heart and Lung Institute, Imperial College London, London, UK

${ }^{19}$ Environmental Health Reference Centre, Regional Agency for Environmental

Prevention of Emilia Romagna, Modena, Italy

${ }^{20}$ Directorate of Public Health and Primary Care, Imperial College Healthcare NHS

Trust, London, UK

Acknowledgements We thank all study members and staff involved in data collections in each cohort.

E3N We wish to thank all the women from the E3N study. We also thank Lyan Hoang, Maryvonne Niravong and Marie Fangon for invaluable assistance with the implementation of the study.

ECRHS The ECRHS data incorporated in this analysis would not have been available without the collaboration of the following individuals and their research teams.

ECRHS Co-ordinating centre: P Burney, D Jarvis, S Chinn, J Knox (ECRHS II),

C Luczynska ${ }^{+}$, J Potts.

Steering Committee for ECRHS II: P Burney, D Jarvis, S Chinn, J. M. Anto, I. Cerveri, R. deMarco , T. Gislason, J. Heinrich, C. Janson, N. Kunzli, B. Leynaert,

F. Neukirch, T. Rochat, J. Schouten, J. Sunyer; C. Svanes, P. Vermeire', M. Wjst. Principal Investigators and Senior Scientific Teams for ECRHS II: Australia:

Melbourne (M Abramson, R Woods, EH Walters, F Thien), Belgium: South Antwerp \& Antwerp City (P Vermeire ${ }^{+}$, Weyler, M Van Sprundel, V Nelen), Denmark: Aarhus (EJ Jensen), Estonia: Tartu (R Jogi, A Soon), France: Paris (F Neukirch, B Leynaert, R Liard, M Zureik), Grenoble (I Pin, J Ferran-Quentin), Bordeaux (A Taytard, C Raherison), Montpellier (J Bousquet, P Demoly) Germany: Erfurt (J Heinrich, M Wjst, C Frye, I Meyer) Hamburg (K Richter), Iceland: Reykjavik (T Gislason, E Bjornsson, D Gislason, T Blondal, A Karlsdottir), Italy: Turin (M Bugiani, P Picci oni, E Caria, A Carosso, E Migliore, G Castiglioni), Verona (R de Marco, G Ver lato, E Zanolin, S Accordini, A Poli, V Lo Cascio, M Ferrari), Pavia 
(A Marinoni, S Villani, M Ponzio, F Frigerio, M Comelli, M Grassi, I Cerveri, A Corsico), Netherlands: Groningen \& Geleen (J Schouten, M Kerkhof), Norway: Bergen (A Gulsvik, E Omenaas, C Svanes, B Laerum), Spain: Barcelona (JM Anto, J Sunyer, M Kogevinas, JP Zock, X Basagana, A Jaen, F Burgos), Huelva (J Maldonado, A Pereira, JL Sanchez), Albacete (J Martinez-Moratalla Rovira, E Almar), Galdakao (N Muniozguren, I Urritia), Oviedo (F Payo), Sweden: Uppsala (C Janson, G Boman, D Norback, M Gunnbjornsdottir), Goteborg (K Toren,

L Lillienberg, AC Olin, B Balder, A Pfeifer-Nilsson, R Sundberg), Umea (E Norrman, M Soderberg, K Franklin, B Lundback, B Forsberg, L Nystrom), Switzerland: Basel (N Kunzli, B Dibbert, M Hazenkamp, M Brutsche, U Ackermann-Liebrich); UK: Norwich (D Jarvis, B Harrison), Ipswich (D Jarvis, R Hall, D Seaton), USA: Portland (M Osborne, S Buist, W Vollmer, L Johnson).

${ }^{t}$ Deceased

NHSD We acknowledge the NSHD participants and the NSHD scientific and data collection teams.

SALIA During the last decades, a lot of scientists, study nurses and laboratories were involved in conducting the study. As representatives for all these people, we would like to thank especially Reinhard Dolgner (MD) for organizing the baseline study and Barbara Schulten as study nurse for her help in organizing the follow-up study. We are most grateful for all the women from the Ruhr area and from Borken who participated in the study during decades.

SAPALDIA Study directorate: T Rochat (p), NM Probst Hensch (e/g), JM Gaspoz (c), N Künzli (e/exp), C Schindler(s).

Scientific team: JC Barthélémy (c), W Berger ( $g)$, R Bettschart ( $p)$, A Bircher (a), G Bolognini (p), O Brändli (p), C Brombach (n), M Brutsche (p), L Burdet (p), M Frey $(p)$, U Frey (pd), MW Gerbase (p), D Gold (e/c/p), E de Groot (c), W Karrer (p), R Keller (p), B Knöpfli (p), B Martin (pa), D Miedinger (o), U Neu (exp), L Nicod (p), M Pons (p), F Roche (c), T Rothe (p), E Russi (p), P Schmid-Grendelmeyer (a), A Schmidt-Trucksäss (pa), A Turk (p), J Schwartz (e), D. Stolz (p), P Straehl (exp), JM Tschopp (p), A von Eckardstein (cc), E Zemp Stutz (e).

Scientific team at coordinating centres: M Adam (e/g), E Boes (g), PO Bridevaux (p), D Carballo (c), E Corradi (e), I Curjuric (e), J Dratva (e), A Di Pasquale (s), L Grize (s), D Keidel (s), S Kriemler (pa), A Kumar (g), M Imboden (g), N Maire (s), A Mehta (e), F Meier (e), H Phuleria (exp), E Schaffner (s), GA Thun (g) A Ineichen (exp),

M Ragettli (e), M Ritter (exp), T Schikowski (e), G Stern (pd), M Tarantino (s), M Tsai (e), M Wanner (pa)

(a) allergology, (c) cardiology, (cc) clinical chemistry, (e) epidemiology, (exp) exposure, (g) genetic and molecular biology, (m) meteorology, (n) nutrition, (o) occupational health, (p) pneumology, (pa) physical activity, ( $p d$ ) paediatrics, (s) statistics

The study could not have been done without the help of the study participants, technical and administrative support and the medical teams and field workers at the local study sites.

Local fieldworkers: Aarau: S Brun, G Giger, M Sperisen, M Stahel, Basel: C Bürli, C Dahler, N Oertli, I Harreh, F Karrer, G Novicic, N Wyttenbacher, Davos: A Saner, P Senn, R Winzeler, Geneva: F Bonfils, B Blicharz, C Landolt, J Rochat, Lugano: S Boccia, E Gehrig, MT Mandia, G Solari, B Viscardi, Montana: AP Bieri, C Darioly, M Maire, Payerne: F Ding, P Danieli A Vonnez, Wald: D Bodmer, E Hochstrasser, R Kunz, C Meier, J Rakic, U Schafroth, A Walder.

Administrative staff: C Gabriel, R Gutknecht.

Contributors Conceptualised the study: ALH, YC, ZA-K, MA and the Steering Committee of ESCAPE WP4: NP-H, FK, UK, TS, JS, NK (Chair). Drafted and edited the paper: $Y C, A L H, T S, N K$. Discussed and interpreted the findings: ESCAPE WP4 working group: MA, AB, A-EC, YC, ALH, NP-H, BJ, FK, NK, UK, AM, JS, MS, TS, AV. Cohort data collections: MB, FC-C, BF, MWG, JH, NP-H, RH, DJ, FK, DKuh, NK, UK, TR, CS, JS, ST, AV, RV. Air pollution assessments: RB, BB, MC, AdN, CD, KdH, REDS, VVF, GH, MJN, AR, MSR, DS, MT. Statistical analysis: ZAK, MA, AB, A-EC, YC, BJ, DKei, AM, CS, MS, TS, AV. All authors have revised the paper and approved the final version.

Funding The research leading to these results has received funding from the European Community's Seventh Framework Program (FP7/2007-2011) under grant agreement number: 211250

E3N cohort is being studied with the financial support of the Mutuelle générale de l'éducation nationale, the European Community, the Lique nationale contre le cancer, the Institut Gustave-Roussy, INSERM, and a grant from the World Cancer Research Fund (grant no. 2007/14). The Asthma-E3N study was supported by the Fonds de dotation 'Recherche en Santé Respiratoire'.

ECRHS was supported by the European Commission, as part of their Quality of Life programme.

The coordination of ECRHS II was supported by the European Commission, as part of their Quality of Life programme. The following bodies funded the local studies in ECRHS II in this article.

Albacete-Fondo de Investigaciones Santarias (grant code: 97/0035-01, 13 99/ 0034-01, and 99/0034-02), Hospital Universitario de Albacete, Consejeria de Sanidad. Antwerp_-FWO (Fund for Scientific Research)—Flanders Belgium (grant code: G.0402.00), University of Antwerp, Flemish Health Ministry.
Barcelona-Fondo de Investigaciones Sanitarias (grant code: 99/0034-01, and 99/ 0034-02), Red Respira (RTIC 03/11 ISC IIF). Ciber of Epidemiology and Public Health has been established and founded by Instituto de Salud Carlos III.

Erfurt-GSF-National Research Centre for Environment \& Health, Deutsche Forschungsgemeinschaft (DFG) (grant code FR 1526/1-1), funded by Helmholtz Zentrum Munich and grants from the German Research Foundation (HE3294/10-1).

Galdakao-Basque Health Department.

Grenoble-Programme Hospitalier de Recherche Clinique-DRC de Grenoble 2000 no.

2610, Ministry of Health, Direction de la Recherche Clinique, Ministere de l'Emploi et de la Solidarite, Direction Generale de la Sante, CHU de Grenoble, Comite des Maladies Respiratoires de I'Isere.

Ipswich and Norwich—National Asthma Campaign (UK).

Huelva_Fondo de Investigaciones Sanitarias (FIS) (grant code: 97/0035-01, 99/ 0034-01, and 99/0034-02).

Oviedo_Fondo de Investigaciones Santarias (FIS) (grant code: 97/0035-01, 99/ 0034-01, and 99/0034-02).

Paris-Ministere de l'Emploi et de la Solidarite, Direction Generale de la Sante, UCBPharma (France), Aventis (France), Glaxo France, Programme Hospitalier de Recherche Clinique-DRC de Grenoble 2000 no. 2610, Ministry of Health, Direction de la Recherche Clinique, CHU de Grenoble.

Pavia—Glaxo, Smith \& Kline Italy, Italian Ministry of University and Scientific and Technological Research (MURST), Local University Funding for Research 1998 \& 1999 (Pavia, Italy)

Turin—ASL 4 Regione Piemonte (Italy), AO CTO/ICORMA Regione Piemonte (Italy), Ministero dell'Università e della Ricerca Scientifica (Italy), Glaxo Wellcome spa (Verona, Italy)

Umeå-Swedish Heart Lung Foundation, Swedish Foundation for Health Care Sciences \& Allergy Research, Swedish Asthma \& Allergy Foundation, Västerbotten County Council (ALF).

Verona-University of Verona; Italian Ministry of University and Scientific and Technological Research (MURST); Glaxo, Smith \& Kline Italy.

NSHD, the National Survey of Health and Development was funded by the UK Medical Research Council (MRC). The NSHD and Professors Hardy and Kuh are supported by core funding and grant funding (MC_UU_12019/1, MC_UU_12019/2, MC_UU_12019/4) from the UK Medical Research Council.

SALIA received funds from the German state (NRW) and federal Ministries of the Environment. The follow-up investigation was funded by the DGUV (German statutory accident assurance) VT 266.1.

SAPALDIA received funds from the Swiss National Science Foundation (grants no 33CSCO-134276/1, 33CSCO-108796, 3247BO-104283, 3247BO-104288, 3247BO-104284, 3247-065896, 3100-059302, 3200-052720, 3200-042532, 4026-028099), the Federal Office for Forest, Environment and Landscape and several Federal and Cantonal authorities; The Swiss National Science Foundation and German research Foundation D-A-CH grant no 32473BM-133148.

Measurements and models for PM in Grenoble (ECRHS) were funded by Region Rhônes-Alpes.

Ethics approval Ethical approval was obtained for each of five participating cohorts in this study.

Provenance and peer review Not commissioned; externally peer reviewed.

Data sharing statement The ESCAPE air pollution data are available for use in future research projects on application to the ESCAPE steering committee (PI Burt Brunekreef).

\section{REFERENCES}

1 Definition and classification of chronic bronchitis for clinical and epidemiological purposes. A report to the Medical Research Council by their Committee on the Aetiology of Chronic Bronchitis. Lancet 1965;1:775-9.

2 Vestbo J, Prescott E, Lange P. Association of chronic mucus hypersecretion with FEV1 decline and chronic obstructive pulmonary disease morbidity. Copenhagen City Heart Study Group. Am J Respir Crit Care Med 1996;153:1530-5.

3 Calverley PM. Cough in chronic obstructive pulmonary disease: is it important and what are the effects of treatment? Cough 2013;9(1):17.

4 Ryan NM, Birring SS, Gibson PG. Gabapentin for refractory chronic cough: a randomised, double-blind, placebo-controlled trial. Lancet 2012;380:1583-9.

5 Cerveri I, Accordini S, Verlato G, et al. Variations in the prevalence across countries of chronic bronchitis and smoking habits in young adults. Eur Respir $J$ 2001;18:85-92. 
6 Schikowski T, Mills IC, Anderson HR, et al. Ambient air pollution: a cause of COPD? Eur Respir J 2014;43:250-63.

7 Jacquemin $B$, Schikowski $T$, Carsin $A E$, et al. The role of air pollution in adult-onset asthma: a review of the current evidence. Semin Respir Crit Care Med 2012:33:606-19.

8 Ghio AJ, Huang YC. Exposure to concentrated ambient particles (CAPs): a review. Inhal Toxicol 2004;16:53-9.

9 Valavanidis A, Fiotakis K, Vlachogianni T. Airborne particulate matter and human health: toxicological assessment and importance of size and composition of particles for oxidative damage and carcinogenic mechanisms. J Environ Sci Health C Environ Carcinog Ecotoxicol Rev 2008;26:339-62.

10 Abbey DE, Hwang BL, Burchette RJ, et al. Estimated long-term ambient concentrations of PM10 and development of respiratory symptoms in a nonsmoking population. Arch Environ Health 1995:50:139-52.

11 Abbey DE, Ostro BE, Petersen F, et al. Chronic respiratory symptoms associated with estimated long-term ambient concentrations of fine particulates less than 2.5 microns in aerodynamic diameter (PM2.5) and other air pollutants. J Expo Anal Environ Epidemiol 1995;5:137-59.

12 Abbey DE, Petersen F, Mills PK, et al. Long-term ambient concentrations of total suspended particulates, ozone, and sulfur dioxide and respiratory symptoms in a nonsmoking population. Arch Environ Health 1993;48:33-46.

13 Bayer-Oglesby L, Schindler C, Hazenkamp-von Arx ME, et al. Living near main streets and respiratory symptoms in adults: the Swiss Cohort Study on Air Pollution and Lung Diseases in Adults. Am J Epidemiol 2006;164:1190-8.

14 Bennett CM, Simpson P, Raven J, et al. Associations between ambient PM2.5 concentrations and respiratory symptoms in Melbourne, 1998-2005. J Toxicol Environ Health A 2007;70:1613-18.

15 Bentayeb M, Helmer C, Raherison C, et al. Bronchitis-like symptoms and proximity air pollution in French elderly. Respir Med 2010;104:880-8.

16 Euler GL, Abbey DE, Hodgkin JE, et al. Chronic obstructive pulmonary disease symptom effects of long-term cumulative exposure to ambient levels of total oxidants and nitrogen dioxide in California Seventh-Day Adventist residents. Arch Environ Health 1988;43:279-85.

17 Lindgren A, Stroh E, Montnemery $\mathrm{P}$, et al. Traffic-related air pollution associated with prevalence of asthma and COPD/chronic bronchitis. A cross-sectional study in Southern Sweden. Int J Health Geogr 2009;8:2.

18 Mann SL, Wadsworth ME, Colley JR. Accumulation of factors influencing respiratory illness in members of a national birth cohort and their offspring. J Epidemiol Community Health 1992;46:286-92.

19 Nachman KE, Parker JD. Exposures to fine particulate air pollution and respiratory outcomes in adults using two national datasets: a cross-sectional study. Environ Health 2012;11:25

20 Nakai S, Nitta H, Maeda K. Respiratory health associated with exposure to automobile exhaust. III. Results of a cross-sectional study in 1987, and repeated pulmonary function tests from 1987 to 1990 . Arch Environ Health 1999:54:26-33

21 Nitta H, Sato T, Nakai S, et al. Respiratory health associated with exposure to automobile exhaust. I. Results of cross-sectional studies in 1979, 1982, and 1983. Arch Environ Health 1993:48:53-8.

22 Schikowski T, Ranft U, Sugiri $D$, et al. Decline in air pollution and change in prevalence in respiratory symptoms and chronic obstructive pulmonary disease in elderly women. Respir Res 2010;11:113.

23 Schikowski T, Sugiri D, Ranft U, et al. Long-term air pollution exposure and living close to busy roads are associated with COPD in women. Respir Res 2005:6:152.

24 Schindler C, Keidel D, Gerbase MW, et al. Improvements in PM10 exposure and reduced rates of respiratory symptoms in a cohort of Swiss adults (SAPALDIA). Am J Respir Crit Care Med 2009;179:579-87.

25 Sunyer J, Jarvis D, Gotschi T, et al. Chronic bronchitis and urban air pollution in an international study. Occup Environ Med 2006;63:836-43.

26 Zemp E, Elsasser S, Schindler C, et al. Long-term ambient air pollution and respiratory symptoms in adults (SAPALDIA study). The SAPALDIA Team. Am J Respir Crit Care Med 1999;159(4 Pt 1):1257-66.

27 Hazenkamp-von Arx ME, Schindler C, Ragettli MS, et al. Impacts of highway traffic exhaust in alpine valleys on the respiratory health in adults: a cross-sectional study. Environ Health 2011:10:13.

28 Beelen R, Hoek G, Vienneau D, et al. Development of NO2 and NOx land use regression models for estimating air pollution exposure in 36 study areas in Europe - The ESCAPE project. Atmos Environ 2013;72:10-23.

29 Eeftens M, Beelen R, de Hoogh K, et al. Development of Land Use Regression models for PM(2.5), PM(2.5) absorbance, PM(10) and PM(coarse) in 20 European study areas; results of the ESCAPE project. Environ Sci Technol 2012;46: 11195-205.

30 Brunekreef B, Forsberg B. Epidemiological evidence of effects of coarse airborne particles on health. Eur Respir J 2005;26:309-18.

31 Gerlofs-Nijland ME, Dormans JA, Bloemen HJ, et al. Toxicity of coarse and fine particulate matter from sites with contrasting traffic profiles. Inhal Toxicol 2007;19:1055-69.

32 Jalava PI, Salonen RO, Pennanen AS, et al. Heterogeneities in inflammatory and cytotoxic responses of RAW 264.7 macrophage cell line to urban air coarse, fine, and ultrafine particles from six European sampling campaigns. Inhal Toxicol 2007;19:213-25.

33 Gulliver J, de Hoogh K, Hansell A, et al. Development and Back-Extrapolation of NO2 Land Use Regression Models for Historic Exposure Assessment in Great Britain. Environ Sci Technol 2013;47:7804-11.

34 Eeftens $\mathrm{M}$, Beelen $\mathrm{R}$, Fischer $\mathrm{P}$, et al. Stability of measured and modelled spatial contrasts in NO(2) over time. Occup Environ Med 2011;68:765-70.

35 Becklake MR, Kauffmann F. Gender differences in airway behaviour over the human life span. Thorax 1999;54:1119-38. 